\title{
Phytochemical Analysis of Medicinal Plants Occurring in Local Area of Mardan
}

Abdul Wadood ${ }^{\text {* }}$, Mehreen Ghufran ${ }^{1}$, Syed Babar Jamal', Muhammad Naeem ${ }^{1}$, Ajmal Khan ${ }^{2}$, Rukhsana Ghaffar $^{3}$ and Asnad $^{1}$

${ }^{1}$ Department of Biochemistry, Abdul Wali Khan University Mardan, Mardan-23200, Pakistan

${ }^{2}$ Hussain Ebrahim Jamal, Research Institute of Chemistry, University of Karachi, Pakistan

${ }^{3}$ Department of Pharmacy, University of Malakand, Pakistan

\begin{abstract}
Medicinal plants have bioactive compounds which are used for curing of various human diseases and also play an important role in healing. Phytochemicals have two categories i.e., primary and secondary constituents. Primary constituents have chlorophyll, proteins sugar and amino acids. Secondary constituents contain terpenoids and alkaloids. Medicinal plants have antifungal, antibacterial and anti-inflammation activities. The present study involves ten different medicinal plants Acacia nilotica, Psidium gujauva, Luffa cylindrical, Morus alba, Morus nigra, Momordica charantia, Fagonia cretica, Punica granatum, Ficus palmate and Prunus persica locally available in Mardan region of Pakistan. The leaves of the selected medicinal plants were washed, air dried and then powdered. The aqueous extract of leaf samples were used for the phytochemical analysis to find out the phytochemical constituents in the plants. The main objective of the research work was to check the presence or absence of the phytochemical constituents in all the selected medicinal plants. The results of the phytochemical analysis of these medicinal plants showed that the terpenoids, phlobatannins, reducing sugar, flavonoids and alkaloids were found to be present in afore mentioned medicinal plants.
\end{abstract}

The phytochemical analysis of the plants is very important commercially and has great interest in pharmaceutical companies for the production of the new drugs for curing of various diseases. It is expected that the important phytochemical properties recognized by our study in the indigenous medicinal plants of Mardan will be very useful in the curing of various diseases of this region.

Keywords: Medicinal plants; Phytochemicals; Anti-fungal; Antibacterial; Anti-inflammation activities

\section{Introduction}

The medicinal plants are useful for healing as well as for curing of human diseases because of the presence of phytochemical constituents [1]. Phytochemicals are naturally occurring in the medicinal plants, leaves, vegetables and roots that have defense mechanism and protect from various diseases. Phytochemicals are primary and secondary compounds. Chlorophyll, proteins and common sugars are included in primary constituents and secondary compounds have terpenoid, alkaloids and phenolic compounds [2]. Terpenoids exhibit various important pharmacological activities i.e., anti-inflammatory, anticancer, anti-malarial, inhibition of cholesterol synthesis, anti-viral and anti-bacterial activities [3]. Terpenoids are very important in attracting useful mites and consume the herbivorous insects [4]. Alkaloids are used as anaesthetic agents and are found in medicinal plants [5]. The Momordica charantia belongs to the Cucurbitaceae family and it has common names such as bitter melon, karela and bitter gourd. More than thousand herbal products of Momordica charantia are used for treatment of diabetic patients and also helpful in lowering of glucose level in the blood [6]. The bioactive constituents are present in Momordica charantia that is charantosides, momordin and goyaglycosides. It also includes terpenoids constituents such as momordicinin, momordenol, momordicin-28, momordicilin and momordol [7-11]. Morus nigra is the botanical name of the mulberry and it belongs to the family Moraceae. Mulberries have shown various biological properties such as anti-inflammatory activities [12]. Guava is the common name of the Psidium guajava and it belongs to the family Myrtaceae. Its phytochemical study shows that its extracts have more than twenty compounds $[13,14]$. Prunus persica belongs to the Rosaceae family. It is used as medicinal plants in African countries and this medicinal plant has shown strong anti-fungal activities [15].

Pomegranate is the common name of the Punica granatum (PG) and belongs to the family Lythraceae. It has much medical significance and used as medicines for centuries [16]. The recent studies have investigated that pomegranates are used for the treatment of a number of diseases e.g., diabetes, dysentery, diarrhea, cough, asthma, bleeding disorders, bronchitis, fever, AIDS, inflammation, ulcers, malaria, prostate cancer, hypertension, atherosclerosis, hyper lipidemia, male infertility, infant brain ischemia and obesity. Fagonia cretica (Zygophyllaceae) is one of the plants which are locally used in Pakistan as a cure of snake bite [17]. Acacia nilotica, it is the member of the Leguminosae family. The subfamily of the Acacia nilotica is Mimosoideae [18]. Luffa cylindrica is the botanical name of the sponge gourds and belongs to Cucurbitaceae family. The fruits of this plant have flat seeds and black in colour which is enclosed by group of fibers [19]. Medicinal and nutritional properties are the characteristics of Luffa cylindrical and seeds of this plant are used for curing of asthma, fever and sinusitis [20]. Morus alba is included in the Moraceae family. Their leaves and fruits are used for curing prematurely grey hair. Its root bark is used by humans for more than 4 thousand years $[21,22]$. Ficus palmate is included in the family of Moraceae and is used as dry vegetable. It is herbaceous perennial plant. Its leaves have hypotensive actions [23].

The main objective of our research work was to analyze the presence

*Corresponding author: Abdul Wadood, Department of Biochemistry, Abdu Wali Khan University Mardan, Mardan-23200, Pakistan, Tel: +92937542195; E-mail: awadood@awkum.edu.pk

Received October 25, 2013; Accepted December 03, 2013; Published December 05, 2013

Citation: Wadood A, Ghufran M, Jamal SB, Naeem M, Khan A, et al. (2013) Phytochemical Analysis of Medicinal Plants Occurring in Local Area of Mardan. Biochem Anal Biochem 2: 144. doi: 10.4172/2161-1009.1000144

Copyright: (c) 2013 Wadood A, et al. This is an open-access article distributed under the terms of the Creative Commons Attribution License, which permits unrestricted use, distribution, and reproduction in any medium, provided the original author and source are credited. 
or absence of different phytochemicals in the selected ten medicinal plants from Mardan region (Pakistan) used for healing and curing of various diseases.

\section{Materials and Methods}

\section{Plant materials}

The present study included plant species which were Acacia nilotica, Punica granatum, Psidium gujauva, Ficus Palmata, Morus alba, Morus nigra, Fagonia cretica, Momordica charantia, Prunus persica and Luffa cylindrical.

\section{Chemicals}

Fehling solution A and Fehling solution B, ethanol, distill water, aqueous $\mathrm{HCl}$, methanol, chloroform, concentrated sulphuric acid, Ammonia solution, picric acid, Hexane.

\section{Sample collection}

Ten medicinal plants were collected locally from the farm lands of Mardan area (Pakistan). The plants were used for the purpose of their phytochemical analysis. The plants collected were identified botanically in department of Botany UCS, Shunkar, Abdul Wali Khan University Mardan. Fresh and tender leaves of selected plants were used for phytochemical analysis. Plant species selected during present investigation were given in Table 1.

\section{Preparation of plant extract}

The leaves of the selected plants were removed from the plants and then washed under running tap water to remove dust. The plant samples were then air dried for few days and the leaves were crushed into powder and stored in polythene bags for use.

The plant powder was taken in a test tube and distilled water was added to it such that plant powder soaked in it and shaken well. The solution then filtered with the help of filter paper and filtered extract of the selected plant samples were taken and used for further phytochemical analysis.

\section{Test for phlobatannins}

Plant powder sample was mixed with distill water in a test tube, then shaked it well, and filtered to take plant extract. Then to each plant extract, $1 \%$ aqueous hydrochloric acid was added and each plant sample was then boiled with the help of Hot plate stirrer. Formation of red colored precipitate confirmed a positive result.

\section{Test for reducing Sugar}

An amount of $0.50 \mathrm{~g}$ of selected plant sample was added in $5 \mathrm{ml}$ of

\begin{tabular}{|c|c|c|c|}
\hline S.No & PLANT SPECIES & LOCAL NAME & PART USED \\
\hline $\mathbf{1}$ & Acacia nilotica & Kikar & Leaves \\
\hline $\mathbf{2}$ & Psidium gujauva & Amrood & Leaves \\
\hline $\mathbf{3}$ & Luffa cylindrica & Torai & Leaves \\
\hline $\mathbf{4}$ & Morus alba & Spin tooth & Leaves \\
\hline $\mathbf{5}$ & Morus nigra & Tor tooth & Leaves \\
\hline $\mathbf{6}$ & Momordica charantia & Karela & Leaves \\
\hline $\mathbf{7}$ & Fagonia cretica & Azghakey & Leaves \\
\hline $\mathbf{8}$ & Punica granatum & Anaar & Leaves \\
\hline $\mathbf{9}$ & Ficus palmata & Enzar & Leaves \\
\hline $\mathbf{1 0}$ & Prunus persica & Shaltalu & Leaves \\
\hline
\end{tabular}

Table 1: Ethnobotanical information of selected medicinal plant species for phytochemical analysis in Mardan area of Pakistan. distilled water. Then $1 \mathrm{ml}$ of ethanol mixed in plant extract. After that we took $1 \mathrm{ml}$ of Fehling solution A and $1 \mathrm{ml}$ of Fehling solution B in a test tube, heated it to boiling and then poured it in the aqueous ethanol extract. When color reaction was observed, it shows a positive result.

\section{Test for terpenoids}

An amount of $0.8 \mathrm{~g}$ of selected plant sample was taken in a test tube, then poured $10 \mathrm{ml}$ of methanol in it, shaken well and filtered to take $5 \mathrm{ml}$ extract of plant sample. Then $2 \mathrm{ml}$ of chloroform were mixed in extract of selected plant sample and $3 \mathrm{ml}$ of sulphuric acid were added in selected sample extract. Formation of reddish brown color indicates the presence of terpenoids in the selected plants.

\section{Test for flavonoids}

For the confirmation of flavonoid in the selected plants, $0.5 \mathrm{~g}$ of each selected plant extract were added in a test tube and $10 \mathrm{ml}$ of distill water, $5 \mathrm{ml}$ of dilute ammonia solution were added to a portion of the aqueous filtrate of each plant extract followed by addition of $1 \mathrm{ml}$ concentrated $\mathrm{H}_{2} \mathrm{SO}_{4}$. Indication of yellow color shows the presence of flavonoid in each extract.

\section{Test for alkaloids}

For the purpose of phytochemical analysis of the selected plants, $0.2 \mathrm{~g}$ of the selected plant samples were added in each test tube and $3 \mathrm{ml}$ of hexane were mixed in it, shaken well and filtered. Then took $5 \mathrm{ml}$ of $2 \% \mathrm{HCl}$ and poured in a test tube having the mixture of plant extract and hexane. Heated the test tube having the mixture, filtered it and poured few drops of picric acid in a mixture. Formation of yellow color precipitate indicates the presence of alkaloids.

\section{Results}

This study has revealed the presence of phytochemicals considered as active medicinal chemical constituents. Important medicinal phytochemicals such as terpenoids, reducing sugar, flavonoids, alkaloids and phlobatannins were present in the samples. The result of the phytochemical analysis shows that the ten plants are rich in at least one of alkaloids, flavonoids, terpenoids, reducing sugars and phlobatannins. Plant Psidium gujauva having all these phytochemicals. The phytochemical screening and qualitative estimation of 10 medicinal plants studied showed that the leaves were rich in phlobatannins, terpenoid, flavonoids, alkaloids and reducing sugar (Table 2).

Phlobatannins are present in Psidium gujauva, Momordica charantia and Prunus persica. Phlobatannins have been reported for its wound healing properties, these are anti-inflammatory and analgesic [23] and antioxidant [24]. Reducing sugars are present only in two plants out of 10 plants i.e., Psidium gujauva and Acacia nilotica. Terpenoids are present in Psidium gujauva, Fagonia cretica and Acacia nilotica. Terpenoids are reported to have anti-inflammatory, anti-viral, anti-malarial, inhibition of cholesterol synthesis and anti-bacterial [3]. Flavonoids are found in Punica granatum, Psidium gujauva, Morus alba, Ficus palmate, Fagonia cretica and Acacia nilotica. Epidemiologic studies recommend that coronary heart disease is opposed by dietary flavonoids. Alkaloids are present in Punica granatum, Psidium gujauva, Morus nigra and Prunus persica as shown in Table 2. Plants having alkaloids are used in medicines for reducing headache and fever. These are attributed for antibacterial and analgesic properties [25].

\section{Discussion}

The research work was carried out on the ten selected medicinal 


\begin{tabular}{|c|c|c|c|c|c|c|}
\hline S.No & Plant species & Phlobatannins & Reducing sugar & Terpenoid & Flavonoids & Alkaloids \\
\hline 1 & Punicagranatum & - & - & - & + & + \\
\hline 2 & Psidium gujauva & + & + & + & + & +++++ \\
\hline 3 & Morusnigra & - & - & - & _- & ++ \\
\hline 4 & Morus alba & - & - & - & + & - \\
\hline 5 & Ficus palmate & - & - & - & + & _- \\
\hline 6 & Momordica charantia & + & - & - & _ & - \\
\hline 7 & Luffa cylindrical & - & - & - & - & - \\
\hline 8 & $\begin{array}{l}\text { Prunus } \\
\text { persica }\end{array}$ & + & - & - & - & +++ \\
\hline 9 & Fagonia cretica & & - & +++ & +++++ & - \\
\hline 10 & Acacia nilotica & - & + & + & + & - \\
\hline
\end{tabular}

$+++=$ shows moderate concentration.

Table 2: Preliminary phytochemical analysis of screened medicinal plant species.

plants which shows that phytochemical constituent's i.e., terpenoids, flavonoids, alkaloids, reducing sugars and phlobatannins are either present or absent in these plants and the results were summarized in Table 2. In our studies it was investigated that alkaloids and flavonoids are present in Punica granatum and phlobatannins, whereas reducing sugars and terpenoids were found to be absent. In previous studies it was reported that flavonoids and terpenoids were present in aqueous extract of the Punica granatum [25] while alkaloids and phlobatannins were found to be absent in it. The recent research studies and previous research studies results were different so it might be due to the change in location and genetic variation due to cross pollination, so their genetic makeup were changed and that is why shows the different results.

Reducing sugars, flavonoids and traces of alkaloids were found to be present in Psidium gujauva according to the previous investigations [26] while in present investigation, reducing sugars, terpenoids, alkaloids, flavonoids and phlobatannins all were present in it and alkaloids were more in concentration as compared to other phytochemicals in Psidium gujauva plant. Alkaloids were present in Morus nigra and the remaining phytochemical constituents were absent. From previous research work it was reported that in the leaves of Morus nigra [27], phytoconstituents i.e., alkaloid contents were found to be present [28].

In our recent research studies Terpenoids, phlobatannins, flavonoids, alkaloids and reducing sugars were absent in Luffa cylindrical, while the previous research studies showed that flavonoids and alkaloids were present in it [29]. The phytochemical analysis of Acacia nilotica showed the presence of terpenoids, reducing sugars and flavonoids. While the previous studies showed that the flavonoids were present [30], the researchers found the same result about the flavonoids and they did not study the remaining phytochemicals in Acacia nilotica. The result obtained from this work revealed that Ficus palmate contained flavonoids. The previous research work showed that flavonoids were present in methanolic extract and petroleum ether extracts of Ficus palmate [31].

It was reported that the ethanolic/aqueous extract of Momordica charantia contained alkaloids, flavonoids and phlobatannins [32] while in our research investigations phlobatannins were found to be present in it. It was investigated that flavonoids were found to be present in Morus alba and the flavonoids in the Morus alba leaves have excellent antioxidant activities and are important bioactive components in Morus alba (mulberry leaves), which can cause inhibition of the oxidative modification of the human lipoproteins [33] while our studies also showed the same results that is flavonoids were detected in it. From previous studies it is confirmed that flavonoids and reducing sugars were present in the methanolic extract of Fagonia cretica while terpenoids were present in the n-hexane extract of the F. cretica [34] and in our recent research studies, it is investigated that flavonoids and terpenoids were found to be present in this plant. In our research studies, alkaloids were found to be present in Prunus persica while the previous studies showed that flavonoids were present in this plant [35].

\section{Conclusion}

The selected ten medicinal plants are the source of the secondary metabolites i.e., alkaloids, flavonoids, terpenoids, phlobatannins and reducing sugars. Medicinal plants play a vital role in preventing various diseases. The antidiuretic, anti-inflammatory, antianalgesic, anticancer, anti-viral, anti-malarial, anti-bacterial and anti-fungal activities of the medicinal plants are due to the presence of the above mentioned secondary metabolites. Medicinal plants are used for discovering and screening of the phytochemical constituents which are very helpful for the manufacturing of new drugs. The previous phytochemical analysis and present studied show nearly the similar results due to the presence of the phytochemical constituents. The phytochemical analysis of the medicinal plants are also important and have commercial interest in both research institutes and pharmaceuticals companies for the manufacturing of the new drugs for treatment of various diseases. Thus we hope that the important phytochemical properties identified by our study in the local plant of Mardan will be helpful in the copping different diseases of this particular region.

\section{Acknowledgement}

We thank Mr. Ashfaq Ahmed and Mr. Muhammad Junaid (Department of Biochemistry, Abdul Wali Khan University Mardan, Pakistan) for their support during conducting the study.

\section{References}

1. Nostro A, Germanò MP, D'angelo V, Marino A, Cannatelli MA (2000) Extraction methods and bioautography for evaluation of medicinal plant antimicrobial activity. Lett Appl Microbiol 30: 379-384.

2. Krishnaiah D, Sarbatly R, Bono A (2007) Phytochemical antioxidants for health and medicine: A move towards nature. Biotechnol Mol Biol Rev 1: 97-104.

3. Mahato SB, Sen S (1997) Advances in triterpenoid research, 1990-1994. Phytochemistry 44: 1185-1236.

4. Kappers IF, Aharoni A, van Herpen TW, Luckerhoff LL, Dicke M, et al. (2005) Genetic engineering of terpenoid metabolism attracts bodyguards to Arabidopsis. Science 309: 2070-2072. 
Citation: Wadood A, Ghufran M, Jamal SB, Naeem M, Khan A, et al. (2013) Phytochemical Analysis of Medicinal Plants Occurring in Local Area of Mardan. Biochem Anal Biochem 2: 144. doi: 10.4172/2161-1009.1000144

Page 4 of 4

5. Hérouart D, Sangwan RS, Fliniaux MA, Sangwan-Norreel BS (1988) Variations in the Leaf Alkaloid Content of Androgenic Diploid Plants of Datura innoxia. Planta Med 54: 14-17.

6. Marles RJ, Farnsworth NR (1995) Antidiabetic plants and their active constituents. Phytomedicine 2: 137-189.

7. Begum S, Ahmed M, Siddiqui BS, Khan A, Saify ZS, et al. (1997) Triterpenes, A sterol and Amonocyclic alcohol from Momordicacharantia. Phytochem 44: 1313-1320.

8. Okabe H, Miyahara Y, Yamauci T (1982) Studies on the constituents of MomordicacharantiaL. Chem Pharm Bull 30: 4334-4340.

9. Kimura Y, Akihisa T, Yuasa N, Ukiya M, Suzuki T, et al. (2005) Cucurbitane-type triterpenoids from the fruit of Momordica charantia. J Nat Prod 68: 807-809.

10. Chang $\mathrm{Cl}$, Chen CR, Liao YW, Cheng HL, Chen YC, et al. (2008) Cucurbitanetype triterpenoids from the stems of momordica charantia. J Nat Prod 71: 13271330.

11. Akihisa T, Higo N, Tokuda H, Ukiya M, Akazawa H, et al. (2007) Cucurbitanetype triterpenoids from the fruits of Momordica charantia and their cancer chemopreventive effects. J Nat Prod 70: 1233-1239.

12. Kim HB, Bang HS, Lee HW, Seuk YS, Sung GB (1999) Chemical characteristics of mulberry syncarp. Korean J Med. Crop Sci 47: 3206-3209.

13. Osman AM, Younes ME, Sheta AE (1974) Triterpenoids of the leaves of Psidium guajava. Phytochem 13: 2015-2016.

14. Begum S, Hassan SI, Siddiqui BS, Shaheen F, Ghayur MN, et al. (2002) Triterpenoids from the leaves of Psidium guajava. Phytochemistry 61: 399-403.

15. Caccioni DRL, Tonini G, Guizzardi M (2002) In vitro antifungal activity of some South African medicinal plants. South Afr J Bot 68: 72-76.

16. Orak HH, Demirci $A$, Gümü $T$ (2011) Antibacterial and antifungal activity of Pomegranate (Punicagranatum L. CV.) Peel. EJEAFCh 10: 1958-1969.

17. Panhwar $A Q$ and Abro $H$ (2007) Ethnobotanical studies of MahalKohistan. Pak J Bot 39: 2301-2315.

18. Brenan JPM (1983) Manual on the taxonomy of Acacia species, present taxonomy of four species of Acacia, FAO, Rome, Italy 42.

19. Stephens JM (2003) Gourd Luffa-Luffa cylindrical, Luffaaegyptica and Luffaacutangula. J Hortic Sci Univ Florida 3: 19-21.

20. Sashikala GD, Kottai AM, Satheesh DK, Rekha S, Indhumathy, et al. (2009) Studies on the antibacterial and antifungal activities of the ethanolic extracts of Luffacylindrica(Linn) fruit. Int J Drug Dev. Res 1: 105-109.

21. Yogisha S, Raveesha KA (2009) In-vitro antibacterial effect of selected medicinal plant extracts. J Nat Prod 2: 64-69.
22. Singab AN, El-Beshbishy HA Yonekawa M, Nomura T, Fukai T (2005) Hypoglycemic effect of Egyptian Morus alba root bark extract: effect on diabetes and lipid peroxidation of streptozotocin-induced diabetic rats. J Ethnopharmacol 100: 333-338.

23. Ayinde BA, Omogbai EK, Amaechina FC (2007) Pharmacognosy and hypotensive evaluation of Ficus exasperata Vahl (Moraceae) leaf. Acta Po Pharm 64: 543-546.

24. Okwu DE, Okwu ME (2004) Chemical composition of SpondiasmombinLinn. Plants parts. J Sust Agric Environ 6: 140-147.

25. Pietta PG (2000) Flavonoids as antioxidants. J Nat Prod 63: 1035-1042.

26. Gill LS (1992) Ethanomedical uses of plants in Nigeria. University of Benin Press, Benin City Nigeria 10-30

27. Rajan S, Mahalakshmi S, DeepaVm, Sathya K, Shajitha S, et al. (2011) Antioxidant potentials of Punica granatum Fruit Rind Extracts. Int J Pharm Pharm Sci 3: 82-88.

28. Birdi T, Daswani $P$, Brijesh S, Tetali $P$, Natu A, et al. (2010) Newer insights into the mechanism of action of Psidium guajava $L$. leaves in infectious diarrhoea BMC Complement Altern Med 10: 33.

29. Said O, Khalil K, Fulder S, Azaizeh H (2002) Ethnopharmacological survey of medicinal herbs in Israel, the Golan Heights and the West Bank region. J Ethnopharmacol 83: 251-265

30. Imran M, Khan H, Shah M, Khan R, Khan F (2010) Chemical composition and antioxidant activity of certain Morus species. J Zhejiang Univ Sci B 11: 973-980.

31. Balakrishnan N, Sharma A (2013) Preliminary phytochemical and pharmacological activities of Luffa cylindricaL Fruit. Asian J Pharm Clin Res 6: 113-116.

32. Jacknoon AA, Esam AE, Mohammed AM, Hamdi OAA, Yahaya AH (2012) A preliminary qualitative study of two common Acacia species in Sudan. E- $J$ Chem 9: 851-856.

33. Swapana N, Jotinkumar T, Devi CB, Singh MS, Singh SB, et al. (2012) Total Phenolic, Total Flavonoid Contents And Antioxidant Activity Of A Few Indigenous Fruits Grown In Manipur. The bio scan 7: 73-76.

34. Adeoti TK, Oyedapo O (2012) Biochemical effects of saponins isolated from Momordica charantia. Med Chem \& Drug Disc 3: 65-70.

35. Dongdong J, Li S, Gu Z (2009) Preparative Isolation Of Flavonoids From Mulberry (Morus Alba L.) Leaves By Macroporous Resin Adsorption. J Food Process Eng 34: 1319-1337. 